\title{
SOLUBILITY AND BOILING-POINT
}

BY OLIVER W. BROWN

It has been shown by Steuber that, when sodium chlorid or sugar is added to aqueous alcohol, the salt and the sugar increase the partial pressure of the alcohol and the boiling point does not rise as much as when pure water is taken. A natural conclusion to be drawn from these experiments is that the disturbing influence of the alcohol would be less if the substance aclded were soluble both in alcohol and in water. This can readily be realized with urea and, at the suggestion of Professor Bancroft, I have made some boiling point determinations with potasssium chlorid and with urea in aqueous alcohol. Urea is especially adapted for such work because it gives excellent results with pure water. The measurements were made with the Beckmann apparatus.

The results with potassium chlorid are given in Table I. In the table $g$ denotes the grams of salt in one hundred grams of aqueous alcohol and $\Delta$ the rise of boiling point. The concentration of the aqueous alcohol was not determined accurately but was roughly fifty percent by volume.

TABLE I

Barometer $741.6 \mathrm{~mm}$

\begin{tabular}{c|c|r}
$g$ & $\Delta$ & $-g / \Delta$ \\
\hline 0.6054 & $-0.06^{\circ}$ & 10.09 \\
1.1910 & -0.13 & 9.16 \\
1.8406 & -0.18 & 10.22 \\
2.4984 & -0.25 & 9.99
\end{tabular}

It is seen from this table that the addition of potassium chlorid low-

Jour. Phys. Chem. 1, 643, I 897 . 
ers the boiling point instead of raising it and that the lowering is proportional to the concentration for this particular case.

The aqueous alcohol used in the determinations with urea was also about fifty percent by volume, that used for the experiments recorded in Table II being however a little more dilute than that used for the experiments in Table III. In both these tables $g$ denotes the number of grams of urea in hundred grams of aqueous alcohol; $\Delta$ the rise of boiling point and $K$ a constant calculated from the formula, $K=M \frac{\Delta}{g}$, where $M$ is the reacting weight of urea.

TABLE II

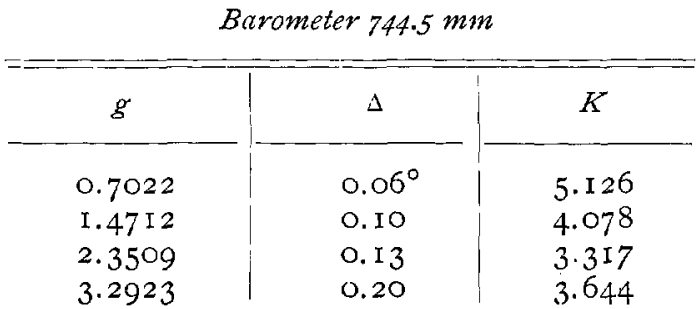

TABLE III

Barometer $744.8 \mathrm{~mm}$

\begin{tabular}{c|c|c}
\hline \hline$g$ & $\Delta$ & $K$ \\
\hline 0.3706 & $0.026^{\circ}$ & 4.209 \\
1.1200 & 0.070 & 3.750 \\
2.3058 & 0.141 & 3.660 \\
3.6562 & 0.210 & 3.446 \\
6.2713 & 0.370 & 3.539
\end{tabular}

It will be noticed that the boiling point rises, in sharp contradistinction to the experiments with potassium chlorid. The values for $K$ decrease with increasing concentration and seen to pass through a minimum just before the last measurement in each table. This calls for further investigation. It is a rather interesting fact that for these particular mixtures of alcohol and water the values of $K$ for infinite dilution are almost identical with the value 5.2 which

rThis has already been observed. Miller. Jour. Phys. Chem. I, 64I (1897). 
would be obtained if we had pure water instead of aqueous alcohol. It seems probable that this is only a coincidence but a more extended study of this point is now being made in this laboratory. With dilute solutions of aqueous alcohol the difference between the behavior of potassium chlorid and of urea would not be so marked. The potassium chlorid would reduce the partial pressure of the water vapor and increase that of the alcohol vapor. The urea would lower the partial pressure of the water to a less extent than did the potassium chlorid, but, on the other hand, it would also decrease the partial pressure of the alcohol. What the result would be in the two cases can not be predicted as yet. With fifty percent alcohol it has been shown that the two substances produce very different effects. It is conceivable however that concentrations might be found such that addition of equivalent quantities of potassium chlorid and of urea might produce equal changes in the boiling point. The partial pressures would not be the same in the two cases, though the total pressures would be.

Cornell University

\section{CORRECTION}

BY WILDER D. BANCROFT

My attention has been called by Professor H. W. Bakhuis Roozeboom to the fact that lead iodid crystallizes in the anhydrous form from aqueous solutions, and not with two of water. In my book 'The Phase Rule) and Mr. Talmadge's paper lead iodid should be substituted in all cases where hydrated lead iodid occurs. In my second paper on Solids and Vapors ${ }^{2}$ the special conclusions based on the assumption of hydrated lead iodid as a solid phase become valueless except in so far as they illustrate the method of attacking such problems.

IJour. Phys. Chem. I, 493 (1897).

2Jour. Phys. Chem. 1, 344 (I897). 